\title{
Relação entre amônia arterial e P300
}

A encefalopatia hepática é uma complicação freqüente das afecções do fígado e sua detecção especialmente nos estágios iniciais não é tarefa simples ${ }^{1}$. Um problema importante provavelmente relacione-se ao entendimento incompleto da fisiopatologia desta entidade clínica. Dentre os instrumentos utilizados para abordagem diagnóstica são utilizados registros eletrofisiológicos da atividade elétrica cerebral, quer sob a forma de eletrencefalografia por análise subjetiva ou quantificada quer por potenciais evocados cerebrais. Destes últimos destaca-se o registro dos chamados potenciais endógenos ou cognitivos como o P300.

Tem sido descrito na literatura uma entidade clínica, designada como encefalopatia hepática mínima, na qual em pacientes cirróticos algumas anormalidades somente são detectadas através de avaliações psicométricas, neuropsicológicas ou neurofisiológicas, que são consideradas como evidencias sub-clínicas de encefalopatia ${ }^{1}$. A importância desta detecção reside na possibilidade de interferência com o afeto, o comportamento, habilidade para dirigir e disturbios do ciclo vigíliasono em pacientes cujas avaliações clínicas neuropsiquiatricas de rotina encontram-se normais.

O papel específico do registro do potencial evocado P300 ainda não está claro na avaliação desta entidade ${ }^{2,3}$, embora tenha sido recomendado em consenso por especialistas ${ }^{1}$; no presente fascículo deste periódico Bragagnolo Júnior et al. ${ }^{4}$ reportam os achados em um grupo de pacientes hepatopatas, no qual conseguem mostrar a existência de uma possível correlação entre os níveis de amônia arterial e a latência do P300, novamente de acordo com outros trabalhos, aparentemente sem relação com as escalas de gravidade clínicas utilizadas.

Embora algumas correlações tenham sido descritas entre os diferentes testes é bastante claro na literatura que existe uma certa independência dos diferentes testes, isto é são detectadas diferentes associações de anormalidades entre os diferentes testes (psicométricos, neuropsicológicos e eletrofisiológicos) e o quadro clínico ${ }^{3}$. Neste contexto o achado de Bragagnolo Júnior et al. ${ }^{4}$ adiciona uma nova faceta a ser investigada que é a possível relação entre o nível de amônia arterial e a latência do P300 para a qual os autores sugerem uma tentativa de explicação no final da discussão.

\section{REFERÊNCIAS BIBLIOGRÁFICAS}

1.Ferenci P, Lockwood A, Mullen K, Tarter R, Weissenborn K, Blei AT. Hepatic encephalopathy - definition, nomenclature, diagnosis, and quantification: final report of the working party at the 11th World Congresses of Gastroenterology, Vienna, 1998. Hepatology 2002;35:716-21.

2.Saxena N, Bhatia M, Joshi YK, Garg PK, Tandon RK. Utility of P300

auditory event related potential in detecting cognitive dysfunction in patients with cirrhosis of the liver. Neurol India 2001;49:350-4

3.Amodio P, Valenti P, Del Piccolo F, Pellegrini A, Schiff S, Angeli P, et al. P300 latency for the diagnosis of minimal hepatic encephalopathy: Evidence that spectral EEG analysis and psychometric tests are enough. Digest Liver Dis 2005;37:861-8.

4.Bragagnolo Júnior MA, Teodoro V, Lucchesi LM, Santos RF, Feldner ACCA, Ribeiro TCR, et al. Correlação entre a amônia e o potencial evocado relacionado a eventos (P300) em pacientes cirróticos. Rev Neurocienc 2009;17:122-7.

Gilberto Mastrocola Manzano
SEPENC - UNIFESP - EPM 